Gusti Irhamna Husin: Pemikiran Tentang Sistem dan Kelembagaan Pendidikan Islam di Masa Rasulullah pada Periode Mekkah dan Periode Madinah

\title{
PEMIKIRAN TENTANG SISTEM DAN KELEMBAGAAN PENDIDIKAN ISLAM DI MASA RASULULLAH PADA PERIODE MEKKAH DAN PERIODE MADINAH
}

\author{
Oleh \\ Gusti Irhamna Husin*1
}

\begin{abstract}
Abstrak
Sistem pendidikan Islam dimulai ketika diutus Nabi Muhammad Saw menjadi Rasul. Pendidikan Islam merupakan sistem tersendiri di antara berbagai sistem yang ada di dunia ini. Pendidikan pada zaman Rasulullah terbagi dua periode yaitu periode Mekkah selama 13 tahun dan periode Madinah selama 10 tahun. Pendidikan pada zaman Rasulullah diwarnai beberapa lembaga yaitu dar Arqam, Kuttab, Mesjid dan Suffah. Setiap lembaga mempunyai karakteristik masing-masing. Lembaga pendidikan pad periode Mekkah berpusat pada pendidikan aqidah dan dilaksanakan di Dar Arqam. Sedangkan lembaga pendidikan Kuttab menitikberatkan pada pendidikan baca tulis. Lembaga pendidikan periode Madinah berpusat pada pendidikan ibadah dan muamalah (sosial). Mesjid pada zaman Rasulullah menjadi central pada lembaga pendidikan. Sedangkan Suffah sebagai pendidikan menghafal Alquran sekaligus basehome bagi kaum Muhajirin yang masih belum memiliki rumah sendiri di kota Madinah. Model pengajaran pada saat itu berbentuk Teacher Center. Model Teacher Center adalah proses pembelajaran dan pengajaran berpusat pada guru karena Nabi Muhammad SAW langsung menerima wahyu dari Allah SWT melalui perantara malaikat Jibril. metode yang digunakan diantaranya: Istima', domonstrasi, cerita, peneladanan, nasehat, pembiasaan dan hadiah dan hukuman. Lembaga yang ada pada zaman Rasulullah diteruskan dan dikembangkan oleh para sahabat dan penerusnya sehingga kita bisa merasakan pendidikan Islam pada zaman sekarang.
\end{abstract}

\section{Kata Kunci: lembaga, Pendidikan, Islam}

\section{A. Latar Belakang}

Islam sesungguhnya lebih dari sekedar agama, ia adalah suatu peradaban yang sangat luar biasa. Itulah ungkapan dari H.A.R Gibb dalam bukunya Whither Islam. Dengan hadirnya Islam maka muncullah peradaban Islam

- $\quad$ Penulis adalah alumni IAIN Antasari Banjarmasin dan sekarang menjadi dosen tetap di STAI Al-Jaami' Banjarmasin. Penulis sekarang melanjutkan kuliah Strata 3 di UIN Antasari Banjarmasin Program Studi Pendidikan Agama Islam.

Jurnal Ilmiah Al QALAM, Vol. 11, No. 24, Juli-Desember 2017 
Gusti Irhamna Husin: Pemikiran Tentang Sistem dan Kelembagaan Pendidikan Islam di Masa Rasulullah pada Periode Mekkah dan Periode Madinah

Nabi Muhammad saw adalah seorang pemimpin agung, manusia besar dan jenius, kenyataan ini diakui oleh kawan dan lawan. Tidak heran pada masa Madinah Islam adalah Negara yang kuat, tempat yang aman untuk berlindung dan tempat yang ditakuti oleh musuh-musuh pada masa itu.

Oleh karena itu, kita sebagai pengikut patut mengetahui seluk-beluk Rasulullah karena beliau adalah suri tauladan bagi kita. Sebagaimana tertulis di dalam al-Qur'an sebagai berikut:

Sesungguhnya pada diri Rasulullah terdapat suri tauladan yang baik bagi kalian, (yaitu) bagi orang yang mendambakan (rahmat) Allah serta hari akhir (yakni kebahagiaan hidup di akherat) dan ia senantiasa ingat kepada Allah. (QS. Al-Ahzab: 21)

Membicarakan sejarah, hal yang sangat penting dikemukakan adalah mengenai latar belakang sosio-kultural.

Arabia tercatat dalam sejarah merupakan kawasan tandus yang sangat gersang. ${ }^{2}$ Masyarakat Arab juga menamai kawasannya dengan sebutan jazirah arab yang berarti pulau Arab. ${ }^{3}$

Jazirah Arab sebelum Islam diapit 2 kerajaan besar, kerajaan Romawi Timur di sebelah Barat meliputi: Turki, Eropa, Asia Kecil, Siria,

2 Ibn Khaldun, memberikan uraian panjang mengenai dampak lingkungan terhadap pembentukan kepribadian manusia. Lingkungan yang panas dan tandus menurutnya telah menimbulkan watak keras dan pantang menyerah bagi masyarakat yang mendiaminya. Sebaliknya kawasan tropis yang subur biasanya melahirkan watak tenang dan kurang agresif. Lihat dalam Ibn Khaldun, Muqaddimah, terj. Ahmadie Thoha, Cet. II. (Jakarta: Pustaka Firdaus, 2002), h. 97

${ }^{3}$ Sebagian sejarawan menamai jazirah Arab dengan sebutan "Sibhul Jazirah" yang berarti semenanjung Arab. Lihat dalam buku Ahmad Syalabi, Sejarah Kebudayaan Islam I, Cet IX (Jakarta: al- Husna, 1997), h. 30

Jurnal Ilmiah Al QALAM, Vol. 11, No. 24, Juli-Desember 2017 
Gusti Irhamna Husin: Pemikiran Tentang Sistem dan Kelembagaan Pendidikan Islam di Masa Rasulullah pada Periode Mekkah dan Periode Madinah

Mesir, Afrika dan Etiopia. Sedangkan kerajaan yang kedua adalah Persia meliputi: Iran, Irak dan Wilayah Teluk Persia dan sebagian jazirah Arab. ${ }^{4}$

Secara sosial bangsa arab mempunyai kelebihan dan kekurangan. Kelebihan dan kekurangan tersebut secara detail diungkapkan Rustam Ibrahim sebagai berikut:

1. Halus tutur bahasanya, mereka sudah mempunyai kesusteraan tinggi. Terbukti dengan banyaknya ahli sastra dan perlombaan pada saat itu.

2. Sangat hormat pada tamu. Mereka mempersiapkan segala keperluan tamu.

3. Suka berterus terang menyatakan apa yang ada dihati mereka.

4. Berani dan setia pada kelompoknya.

Sedangkan kekurangannya adalah sebagai berikut:

1. Hidup menyamun dan merampok kabilah di padang pasir.

2. Memandang rendah kaum wanita.

3. Suka berjudi dan minum khamar

4. Tidak tunduk pada pemerintahan

5. Sangat mudah tersinggung. ${ }^{5}$

\section{B. Pembahasan}

\section{Periode Mekkah}

Menjelang usianya yang keempat puluh, Rasulullah sudah terlalu biasa memisahkan diri dari kegalauan masyarakat, berkontemplasi ke gua Hira, beberapa kilometer di Utara Mekkah. Pada tanggal 17 Ramadhan tahun 611 M, malaikat Jibril muncul dihadapannya, menyampaikan wahyu

${ }^{4}$ Istianah Abu Bakar, M.Ag, Sejarah Peradaban Islam, Cet I, (Malang: UIN Malang Press, 2008), h. 3

${ }^{5}$ Rustam Ibrahim, Sejarah Islam, (Jakarta: Djajamurni, 1971), h. 17-18

Jurnal Ilmiah Al QALAM, Vol. 11, No. 24, Juli-Desember 2017 
Gusti Irhamna Husin: Pemikiran Tentang Sistem dan Kelembagaan Pendidikan Islam di Masa Rasulullah pada Periode Mekkah dan Periode Madinah

yang pertama. $^{6}$ Dengan turunnya wahyu pertama itu, berarti nabi Muhammad saw telah dipilih Tuhan sebagai nabi. ${ }^{7}$ Setelah wahyu pertama datang, kemudian selang beberapa lama wahyu kedua turun. ${ }^{8}$

Dengan turunnya perintah itu, mulai lah Rasulullah berdakwah. pertama-tama, beliau melakukannya secara diam-diam di lingkungan sendiri dan dikalangan rekan-rekannya. Mula-mula istrinya, Khadijah, sepupunya Ali bin Abi Thalib yang berumur 10 tahun. Kemudian Abu Bakr (Abdullah bin abi Kuhafah Usman bin amir bin amru bin ka'ab bin sa'ad bin Taimi bin Marrah bin Ka'ab bin Luai bin Galib. $)^{9}$, Zaid bin Haritsah, ummu aiman. Kemudian Abu bakar berhasil mengislamkan: Usman bin Affan, Zubair bin Awwam, Abdurrahman bin Auf, Sa'ad bin Abi Waqqash, dan Thalhah bin Ubaidillah. ${ }^{10}$

Lembaga pendidikan, setelah banyak orang yang memeluk Islam, lalu nabi Muhammad saw menyediakan rumah al-Arqam bin Abil Arqam ${ }^{11}$ untuk tempat pertemuan sahabat-sahabatnya. Sehingga darul Arqam menjadi lembaga pendidikan pertama dalam sejarah Islam. $^{12}$ Nabi

\footnotetext{
${ }^{6}$ Lihat Alquran surah surah al Alaq: 105

7 Badri yatim. Sejarah Peradaban Islam, (Jakarta: PT RajaGrafindo Persada, 2006), h. 18-19

${ }^{8}$ Lihat Alquran surah al-Muddatsir ayat 1-7

${ }^{9}$ Hafiz jalaluddin as-Syayuthi, التاريخ الخفاءdarul kitab islamiyah, h. 26

${ }^{10}$ Badri yatim. Sejarah Peradaban Islam, Op.Cit, h. 19

${ }^{11}$ Abu Abdillah al-Arqam bin Abi al-Arqam ( الأرقم بن أبي الأرقم) lahir pada tahun
} 673 Masehi. Beliau adalah seorang pengusaha yang berpengaruh dari suku Makhzum dari kota Mekkah. Dalam sejarah Islam, dia orang ketujuh dari As-Sabiqun al-Awwalun. Rumahnya berlokasi di bukit Safa, di tempat inilah para pengikut Muhammad belajar tentang Islam. Sebelumnya rumah al-Arqam ini disebut Dar al-Arqam (rumah Al-Arqam) dan setelah dia memeluk Islam akhirnya disebut Dar al-Islam (Rumah Islam). Lihat www. Ar-Risalah.net

${ }^{12}$ Hasan Abdul 'Ali, At-Tarbiyah al-Islamiyah Fi al-Qurni al Rabi al Hijry, (Mesir: Darul Fikri, 1977), h. 26

Jurnal Ilmiah Al QALAM, Vol. 11, No. 24, Juli-Desember 2017 
Gusti Irhamna Husin: Pemikiran Tentang Sistem dan Kelembagaan Pendidikan Islam di Masa Rasulullah pada Periode Mekkah dan Periode Madinah

Muhammad mengajarkan ${ }^{13}$ dasar-dasar ajaran Islam dan menyampaikan wahyu-wahyu Alquran kepada sahabat di Darul Arqam. ${ }^{14}$

Setelah beberapa lama dakwah tersebut dilaksanakan secara diamdiam turun lah perintah agar nabi menjalankan dakwah secara terbuka. Sebagaimana termaktub di dalam al-Qur'an: sampaikanlah secara terbuka (terang-terangan) semua yang diperintahkan kepadamu dan berpalinglah dari kaum Musyrikin (QS al-hijr:94). Mula-mula ia mengundang dan menyeru kerabatnya dari bani Abdul Muthalib sebanyak 40 orang, ${ }^{15}$ ia mengatakan kepada mereka "saya tidak melihat seorangpun di kalangan Arab yang dapat membawa sesuatu ke tengah-tengah mereka lebih baik dari apa yang saya bawa kepada kalian. Kubawakan kepadamu dunia dan akherat yang terbaik. Tuhan memerintahkan saya mengajak kalian semua. Siapakah di antr kalian yang mau mendukung saya dalam hal ini?” mereka menolak kecuali Ali

Kemudian nabi Muhammad saw berdakwah secara luas kepada masyarakat umum meliputi: para kaum bangsawan, hamba sahaya, kerajaankerajaan lain. Dengan usaha yang gigih, nabi mendapatkan hasil, sedikit demi sedikit pengikut beliau bertambah, sebagian besar adalah wanita, budak, orang yang tak punya.

Dalam dakwah secara terang-terangan beliau mendapat rintangan karena ketidaksukaan mereka melihat bertambahnya pengikut Rasul dari

\footnotetext{
${ }^{13}$ Setelah turun ayat ini Rasulullah saw mulai mengajar sahabatnya. jumlah yang belajar selama 3 tahun setelah kenabian; 53 orang, laki-laki 43 dan wanita 10 orang, Nabi bersama orang yang beriman belajar di rumahnya Al-Arqam bin Abi Arqam. ( Ibnu Hisyam: I, $254-265$ ).

${ }^{14}$ Muhammad Athiyah al-Abrasyi, Dasar-dasar Pokok Pendidikan, alih bahasa Bustami A. Ghani dan Djohan Bahri, (Jakarta: Bulan Bintang, 1970), h. 51

${ }^{15}$ Al-hamid al-husaini, Riwayat Kehidupan Nabi Besar Muhammad saw, (Bandung: Pustaka Hidayah, 2011), h. 356
}

Jurnal Ilmiah Al QALAM, Vol. 11, No. 24, Juli-Desember 2017 
Gusti Irhamna Husin: Pemikiran Tentang Sistem dan Kelembagaan Pendidikan Islam di Masa Rasulullah pada Periode Mekkah dan Periode Madinah

hari ke hari. Menurut Ahmad Syalabi, ada 5 faktor yang mendorong kaum Quraisy menentang seruan Islam diantaranya:

1. Mereka tidak dapat membedakan antara kenabian dan kekuasaan;

2. Rasul menyeru persamaan hak antara kaum bangsawan dan hamba sahaya;

3. Mereka tidak menerima ajaran tentang hari kebangkitan dan pembalasan di akherat;

4. Taklid nenek moyang;

5. Pemahat dan penjual patung merasa dirugikan. ${ }^{16}$

Rintangan juga didapati oleh pengikutnya, kekejaman demi kekejaman, tindakan kekerasan secara fisik juga mereka rasakan, perbuatan kaum Quraisy mendorong nabi untuk mengungsikan sahabat-sahabatnya dari Mekkah, pada tahun kelima kerasulan, nabi menetapkan Habsyah (Ethiopia) sebagai negeri tempat pengungsian karena raja Negus seorang yang adil. Rombongan pertama sebanyak sepuluh orang diantaranya: usman bin Affan berserta Rukayah, Zubair ibn Awwm, dan Abdurrahman ibn 'auf kemudian menyusul rombongan kedua sejumlah 73 laki-laki dan 11 orang perempuan dipimpin oleh ja'far bin abu Thalib. ${ }^{17}$

Pada tahun ke-7 kenabian tanggal 1 muharram, ${ }^{18}$ kaum Musyrik membaikot bani Hasyim, karena bani Hasyim melindungi rasul, pemboikotan itu berupa larangan jual-beli dan memutuskan segala hubungan kepada bani Hasyim dan berlangsung selama 3 tahun,

\footnotetext{
${ }^{16}$ Badri yatim. Sejarah Peradaban Islam..., h. 21

${ }^{17}$ Umar Abdullah al-Jabbar, خلاصة نور اليقين فى سيرة سيد المرسلين (Surabaya: Nurul Hikmah, jld 1), h. 33

${ }^{18}$ Al-hamid al-husaini, Riwayat Kehidupan Nabi Besar Muhammad saw, (Bandung: Pustaka Hidayah, 2011), h. 422
}

Jurnal Ilmiah Al QALAM, Vol. 11, No. 24, Juli-Desember 2017 
Gusti Irhamna Husin: Pemikiran Tentang Sistem dan Kelembagaan Pendidikan Islam di Masa Rasulullah pada Periode Mekkah dan Periode Madinah

Tidak lama pemboikotan berhenti wafat lah paman nabi Abu Thalib dalam usia 78 tahun. Tiga hari setelah itu, khadijah, istri nabi meninggal dunia pula. Peristiwa itu terjadi pada tahun kesepuluh kenabian. Dan disebut tahun berduka. ${ }^{19}$ Menurut Umar Abdul Jabbar: Khadijah meninggal setelah sebulan kemudian Abu Thalib. ${ }^{20}$

Setelah wafatnya dua orang yang penting dalam hidup Rasul, beliau tetap berdakwah ke luar kota untuk menyebarkan agama Islam. Termasuk ke kota Tha'if.

Tha'if adalah kota ketiga sesudah Mekkah dan Madinah yang berbahagia karena pernah didatangi Rasul. Dua kali beliau pergi ke kota tersebut. Yang pertama pada bulan syawal tahun ke-10 kenabian, dan kedua pada bulan Syawal tahun 5 H. Tha'if terletak kurang lebih 75 mil di sebelah tenggara kota Mekkah, di atas tanah pegunungan Ghazwan yang puncaknya berketinggian kurang lebih 6000 kaki.

Dahulunya kota itu bernama Huwwai. Kaum hartawan Quraisy banyak yang membangun gedung-gedung di kota tersebut sebagai tempat peristirahatan di musim panas. ${ }^{21}$

Rasulullah saw setiba di Tha'if, bertemu dengan beberapa pemimpin bani Tsaqif dan mengutarakan maksud kedatangannya, tetapi mereka menolak dengan kasarnyadan memerintahkan para gelandangan dan budakbudak mereka untuk memaki-maki, mengolok-olok, dan melempari beliau dengan batu hingga kedua kaki beliau berdarah dan Zaid dan Haritsah yang melindung nabi mendapatkan beberapa luka di kepala. 2006), h. 23

${ }^{19}$ Badri yatim. Sejarah Peradaban Islam, (Jakarta: PT RajaGrafindo Persada,

${ }^{20}$ Umar Abdullah al-Jabbar, خلاصة نور اليقين فى سيرة سيد المرسلبن (Surabaya: Nurul Hikmah, jld 1), h.39

21 Al-hamid al-husaini, Riwayat Kehidupan Nabi Besar Muhammad saw, (Bandung: Pustaka Hidayah, 2011), h. 437

Jurnal Ilmiah Al QALAM, Vol. 11, No. 24, Juli-Desember 2017 
Gusti Irhamna Husin: Pemikiran Tentang Sistem dan Kelembagaan Pendidikan Islam di Masa Rasulullah pada Periode Mekkah dan Periode Madinah

\section{Periode Madinah}

Berbeda dengan periode Mekkah, pada periode Madinah, Islam merupakan kekuatan politik, karena Rasul saw menjadi kepala negara. Dalam menjalankan tugasnya, pertama, beliau membangun mesjid untuk ibadah, menyatukan umat islam dan tempat musyawarah, karena mesjid menjadi pusat pemerintahan pada masa itu. Kedua, mempersaudarakan antara kaum anshar dan muhajirin. Ketiga, hubungan persahabatan dengan non Islam.

Mesjid sebagai pusat pendidikan pada saat itu melakukan kegiatan halaqoh ta'lim dan pusat kebudayaan masjid juga merupakan sentral kegiatan sosial, politik, budaya dan agama. ${ }^{22}$

Fungsi edukatif masjid pada awal pembinaan Islam masjid merupakan lembaga pendidikan Islam, yakni tempat manusia dididik agar memegang teguh keimanan, cinta ilmu pengtahuan, merealisasikan ketaatan kepada Allah menegakkan syariat Islam.

Di sebelah selatan masjid terdapat satu ruangan yang disebut Suffah yakni tempat tinggal para sahabat miskin yang tidak memiliki rumah namun ada juga beberapa pendudukak Madinah yang mempunyai tempat tinggal dan pekerjaan. Mereka adalah penuntut ilmu yang mencari ketenangan jiwa dan tidak terobsesi indahnya dunia ${ }^{23}$

Selama enam bulan beliau menjadi kepala negara, kehidupan di madinah menjadi tentaram, damai dikarenakan oleh tiga faktor: (1) Pemimpin yang bijaksana (2) kekuatan aqidah kaum muslim (3) kesatuan dan persatuan yang kuat. 1982), h. 199

${ }^{22}$ Muhammad Munir Mursyi, al-Tarbiyah al-Islamiyah, (Kairo: Dar al Kutub,

${ }^{23}$ Hasab Ibrahim hasan, Tarikh al Islamiyah al Siyari al Dini al Tsaqafi wal Ijtima'I, (Mesir: Maktabat al Nahdah, 1976), h. 422

Jurnal Ilmiah Al QALAM, Vol. 11, No. 24, Juli-Desember 2017 
Gusti Irhamna Husin: Pemikiran Tentang Sistem dan Kelembagaan Pendidikan Islam di Masa Rasulullah pada Periode Mekkah dan Periode Madinah

Dengan terbentuknya kota Madinah, Islam pun menjadi semakin kuat, oleh karena itu kaum Musyrikin menjadi takut dan ingin menghancurkan Rasul saw dan kota Madinah.

\section{Analisis}

1. Sistem dan Lembaga Pendidikan Islam pada Zaman Rasulullah

Sistem lembaga pendidikan Islam pada Zaman Rasulullah dibagi menjadi dua periode. Periode pertama di Mekkah dan periode kedua di Madinah. Pada periode Mekkah terdapat dua macam tempat pendidikan, Yaitu:

a. Rumah Arqam Ibn Arqam merupakan tempat pertama berkumpulnya kaum muslimin beserta Rasulullah untuk belajar hokum-hukum dan dasar-dasar ajaran Islam

b. Kuttab. Pendidikan adalah pendidikan formal pada masa itu bahkan ada yang mengatakan sebelum Rasulullah diutus Sudah ada kuttab namun kurang diminati karena kebudayaan mereka adalah berdagang. Kurikulum kutab jauh berbeda dengan pembelajaran di darul Arqam yang membahas hukum-hukum dan dasar-dasar Islam, kuttab hanya sebatas belajar membaca dan menulis untuk anakanak saja pada masa itu.

Kaum Quraisy pada masa itu yang bisa membaca dan menulis baru 17 laki-laki dan 5 orang perempuan. Mereka adalah 1) Umar Ibn Khatab, 2) Ali bin Abi Thalib, 3) Usman Ibn Affan, 4) Abu Ubaidah Ibn Jarrah, 5) Talhah, 6) Yazid Ibn Abu Sofyan, 7) Abu Huzaifah Ibn Utbah, 8) Hatib Ibn Jarrah, 9) Abu Salamah Abd Al-Asad Al-Makhzumi, 10) Aban Ibn Sa'ad Ibn Al-Ash Ibn Sa'd bin Abu Sarh Al-Amiry, 14) Huwaitib Ibn Abd Al-

Jurnal Ilmiah Al QALAM, Vol. 11, No. 24, Juli-Desember 2017 
Gusti Irhamna Husin: Pemikiran Tentang Sistem dan Kelembagaan Pendidikan Islam di Masa Rasulullah pada Periode Mekkah dan Periode Madinah

Uzza, 15) Abu Sufyan Ibn Harb, 16) Mu'awiyah Ibn Abu Sufyan dan 17) Juhaimi Ibn Shalt.

Lima wanita tersebut adalah: 1) Hafsah, 2) Ummi Kulsum Binti Uqbah 3) Aisyah binti Sa'd, 4) Al-Sifa binti Abdullah al-Adawiyah, dan 5) Karimah binti Al-Miqdad. Sedangkan Siti Aisyah dan Umi Salamah, Pandai Membaca Tetapi tidak dapat bisa menulis ${ }^{24}$

Ketika Islam Islam hadir ditengah-tengah mereka Kuttab berubah tidak hanya untuk anak-anak melainkan seluruh elemen masyarakat yang merasa belum bisa baca tulis dan yang ingin belajar.

Lembaga pendidikan zaman Rasulullah pada periode Madinah sebagai berikut:

1) Mesjid. Ketika Rasulullah sampai ke Madinah, pekerjaan pertama adalah membuat mesjid sebagai pusat kegiatan Islam di Madinah. Beberapa fungsi masjid diantaranya adalah:

a. Mesjid sebagai tempat ibadah. Yaitu melakukan kegiatan sholat lima waktu, sholat Jum'at, tarawih, Sholat ied dan adha.

b. Mesjid sebagai pembinaan aqidah. Biasanya nabi membuat halaqoh ta'lim dalam rangka membina aqidah para sahabat dan membacakan Alquran

c. Mesjid menjadi tempat pertemuan atau tempat sahabat saling berkumpul untuk menjalin ukhuwah islamiyah

d. Mesjid sebagai kegiatan sosial misalnya tempat penyaluran sedekah, zakat dan infaq kepada yang berhak diantaraya

${ }^{24}$ Munir Mursi, Al-Tarbiyyah Al-Islamiyyah: Ushuluha wa Tathowwuruha Fi Al Bilad Al-Arabiyyah, (Kairo: Al-Kutub, 1977) h. 3

Jurnal Ilmiah Al QALAM, Vol. 11, No. 24, Juli-Desember 2017 
Gusti Irhamna Husin: Pemikiran Tentang Sistem dan Kelembagaan Pendidikan Islam di Masa Rasulullah pada Periode Mekkah dan Periode Madinah

adalah kaum fakir, miskin, anak yatim yang terlantar dan para janda

e. Menjadikan halaman mesjid menjadi pusat pengobatan bagi masyarakat yang sakit

f. Menjadikan mesjid menjadi tempat pengatur pemerintahan dan perperangan

2) Suffah yaitu suatu tempat yang sudah disediakan oleh Rasulullah untuk kaum muhajirin yang tidak mempunyai rumah dan tempat masyarakat yang ingin masuk Islam. Abu hurairah ditunjuk oleh Rasulullah sebagai penanggung jawab ahlu suffah yang berjumlah relatif antara 60-80. Adapun Ubaid Ibn al-Shamit ditunjukan sebagai guru suffah.

Suffah adalah salah satu tempat yang paling banyak dikunjungi oleh Rasulullah karena beberapa alasan diantaranya adalah

a. Kebanyakan mereka adalah orang yang kurang mampu walaupun ada juga yang kaya

b. Ahlu suffah adalah diantara banyak sahabat yang lebih banyak mencari ketenangan jiwa daripada kebahagiaan dunia

c. Ahlu suffah kegiatan mereka adalah menghafal Alquran

Maka tidak salah Rasulullah jika mendapat hadiah dari sahabat yang kaya, beliau mengambil sedikit buat kebutuhan rumah sisanya diserahkan kepada ahlu Suffah.

3) Kuttab pada periode Madinah mendapatkan perhatian oleh Rasulullah yang lebih serius karena kebanyakan yang masuk Islam adalah warga yang lemah dan buta huruf. Indikator bahwa Rasulullah serius memperhatikan kuttab ketika perang badar ada 70 orang tawanan dari pihak musuh yang dihukum kebeberapa opsi 1)

Jurnal Ilmiah Al QALAM, Vol. 11, No. 24, Juli-Desember 2017 
Gusti Irhamna Husin: Pemikiran Tentang Sistem dan Kelembagaan Pendidikan Islam di Masa Rasulullah pada Periode Mekkah dan Periode Madinah

jika tawanan itu tidak bisa baca tulis maka akan di penjara sekitar mesjid selama beberapa tahun 2) jika tawanan itu bisa baca tulis maka akan diberikan tawaran yaitu apakah ingin mengajari masyarakat Madinah sebanyak 10 orang atau masuk penjara.

2. Dasar pendidikan Islam pada zaman Rasulullah

Pendidikan Islam pada periode Mekkah adalah ajaran tauhid. Pendidikan tauhid merupakan perhatian utama Rasulullah ketika di Mekkah. Pada saat itu masyarakat jahiliyyah sudah banyak yang menyimpang dari ajaran tauhid yang dibawakan oleh nabi Ibrahim.

Menurut Mahmud Yunus, ${ }^{25}$ pendidikan Islam pada periode Mekkah meliputi:

a. Pendidikan keagamaan. Pendidikan ini menekankan penanaman kesadaran bahwa amalan manusia sepenuhnya memiliki kaitan erat dengan Tuhan. Tidak ada amal apapun yang dapat dilepaskan dari pengawasan dan kemudian imbalan yang diberikan Tuhan.

b. Pendidikan akliyah dan ilmiah. Yakni penekanan kembali kepada masyarakat untuk memaksimalkan fungsi akal yang dimiliki dengan mengamati gejala atau peristiwa alam untuk membersihkan diri dari pelakuan khurafat yang membelenggu jiwa, akal dan tindakan. 2011) h. 34

${ }^{25}$ Fatah Syukur, Sejarah Peradaban Islam, (Semarang: PT Pustaka Rizki Putra, Jurnal Ilmiah Al QALAM, Vol. 11, No. 24, Juli-Desember 2017 
Gusti Irhamna Husin: Pemikiran Tentang Sistem dan Kelembagaan Pendidikan Islam di Masa Rasulullah pada Periode Mekkah dan Periode Madinah

c. Pendidikan akhlaq dan budi pekerti. Hal ini berkaitan dengan penataan interaksi hubungan manusia dengan manusia dan hubungan manusia dengan Tuhan.

d. Pendidikan jasmani. Pendidikan jasmani berkaitan dengan pesan awal Islam yang sangan menekankan pentingnya menjaga kebersihan. Kebersihan dalam Islam tidak dibatasi pada jasmani saja melainkan juga mencakup kebersihan rohani.

Pendidikan Islam pada periode Madinah adalah:

1) Pembentukan dan pembinaan masyarakat baru, menuju satu kesatuan sosial dan politik. dalam hal ini nabi melaksanakan pendidikan sebagai berikut:

a. Nabi mengikis habis sisa-sisa permusuhan dan pertengkaran antar suku, dengan jalan mengikat tali persaudaraan di antara mereka.

b. Untuk memenuhi kebutihan hidup sehari-hari, Nabi menganjurkan kepada kaum Muhajirin untuk usaha dan bekerja sesuai dengan kemampuan dan pekerjaan masingmasing seperti waktu Mekkah.

c. Menjalin kerjasama dan tolong menolong dalam membentuk tata kehidupan masyarakat yang adil dan makmur.

d. Sholat Jum'at sebagai media komunikasi seluruh umat Islam.

2) Pendidikan sosial dan kewarganegaraan.

a. Pendidikan ukhuwah antar muslim.

b. Pendidikan kesejahteraan sosial dan tolong menolong.

c. Pendidikan kesejahteraan keluarga kaum kerabat. 
Gusti Irhamna Husin: Pemikiran Tentang Sistem dan Kelembagaan Pendidikan Islam di Masa Rasulullah pada Periode Mekkah dan Periode Madinah

3) Pendidikan anak dalam Islam

a. Agar kita selalu menjaga diri dan anggota keluarga dari api Neraka. (at-Tahrim:6)

b. Agar jangan meninggalkan anak dan keturunan dalam keadaan lemah dan tidak berdaya menghadapi tantangan hidup. (an-Nisa:9)

c. Orang yang dimuliakan Allah adalah orang yang berdoa agar dikaruniai keluarga dan anak keturunan yang menyenangkan hati. (al-Fuqon: 74)

Adapun bentuk-bentuk pendidikan anak dalam Islam sebagaimana digambarkan dalam surat al-Luqman ayat 13-19 sebagai berikut:

1. Pendidikan Tauhid,

2. Pendidikan Shalat,

3. Pendidikan sopan santun keluarga,

4. Pendidikan sopan santun masyarakat,

5. Pendidikan kepribadian.

6. Pendidikan kesehatan

7. Pendidikan akhlak ${ }^{26}$

3. Pendidik dan Peserta didik pada Zaman Rasulullah

Pada zaman Rasulullah pendidikan Islam Berpusat pada satu guru saja yaitu Rasulullah dalam istilah pendidikan “Teacher Center” dimana pendidikan hanya berpusat kepada guru. Setiap permasalah-permasalah yang timbul pada saat itu para sahabat akan langsung datang kepada Rasulullah untuk mendapatkan solusinya. Walaupun ada beberapa kasus

${ }^{26}$ Fatah Syukur, Sejarah Peradaban Islam, (Semarang: PT Pustaka Rizki Putra, 2011), h. 39-40

Jurnal Ilmiah Al QALAM, Vol. 11, No. 24, Juli-Desember 2017 
Gusti Irhamna Husin: Pemikiran Tentang Sistem dan Kelembagaan Pendidikan Islam di Masa Rasulullah pada Periode Mekkah dan Periode Madinah

yang permasalahan itu diserahkan lagi kepada sahabat yang lain untuk memberikan solusinya.

Ketika menyampaikan wahyu, memberikan nasehat di halaqohhalaoh ta'lim Rasulullah mengajarkan pokok-pokok ajaran Islam dengan segenap hati tulus mentransfer apa yang telah diberikan oleh Allah SWT.

Peserta didik yang dimaksud pada zaman Rasulullah adalah para sahabat atau pengikut beliau yang masuk Islam dan percaya akan kenabian terakhir yang diutus oleh Allah SWT.

Para sahabat sangat antusias mendengarkan penjelasan Rasulullah. Suatu ketika Rasulullah memberikan materi pokok aqidah setelah sholat subuh dengan rinci dan tidak terasa waktu dzuhur tiba, Rasullulah dan para sahabat mendirikan Sholat berjama'ah kemudian Rasulullah meneruskan penjelasan beliau sampai waktu asar, kemudian mendirikan sholat berjama'ah asar kemudian Rasulullah meneruskan penjelaskan beliau sampai senja.

Cerita di atas menggambarkan betapa serius dan senangnya para sahabat ketika Rasulullah menjelaskan suatu ilmu bahkan mereka rindu jika beberapa hari tidak bertemu dengan Rasulullah.

4. Materi Pendidikan Islam pada zaman Rasulullah

Materi pendidikan Islam Zaman Rasulullah pada periode Mekkah bertumpu pada Alquran dan Sunnah karena Alquran dan Sunnah Rasulullah merupakan inti sari atau pokok-pokok pendidikan Islam. Sedangkan pada periode Madinah materi pendidikan Islam berkisar pada aspek Keimanan, akhlak, ibadah, mu'amalah, kesehatan jasmani dan rohani, social bahkan politik.

5. Metode Pendidikan Islam pada Zaman Rasulullah 
Gusti Irhamna Husin: Pemikiran Tentang Sistem dan Kelembagaan Pendidikan Islam di Masa Rasulullah pada Periode Mekkah dan Periode Madinah

Metode pendidikan Islam dalam proses penyampaian materi agama di lembaga darul Arqam, mesjid dan Suffah sebagai berikut: 1) Alquran: metode istima', tahfiz dan muroja'ah 2) Muamalah: muhadhoroh dan Mudzakarah.

Bidang keimanan: melalui tanya jawab dengan penghayatan dan didukung dengan bukti-bukti rasional dan ilmiah

Materi ibadah: disampaikan dengan metode demonstrasi dan peneladanan sehingga masyarakat banyak mengikuti.

Bidang akhlak: Nabi menitik beratkan pada metode peneladanan. Nabi tampil dalam kehidupan sebagai orang yang memiliki kemuliaan dan keagungan baik dalam ucapan maupun perbuatan.

Metode pendidikan Islam pada zaman Rasulullah disederhanakan sebagai berikut:

a. Teladan. Allah berfirman di dalam Alquran surah al-Ahzab ayat $21^{27}$ yang isinya kita bisa menyimpulkan bahwa di dalam diri Rasulullah itu terdapat teladan yang baik. Aisyah juga ditanya tentang akhlak Rasulullah. Beliau menjawab bahwa pribadi beliau Alquran.

b. Nasehat. Di dalam jiwa terdapat pembawaan untuk terpengaruh oleh-kata-kata yang di dengar. Semakin sering kita mendengar semakin besar pula dampak pengaruh yang kita rasakan.

c. Hadiah dan sanksi. Salah satu tugas Rasulullah ialah membawa kabar baik dan kabar buruk.

d. Cerita. Metode ini sangat bagus dalam pendidikan, karena dengan bercerita semua peserta didik akan suka dan dapat diambil pelajaran yang baik agar bisa dicontoh maupun 
Gusti Irhamna Husin: Pemikiran Tentang Sistem dan Kelembagaan Pendidikan Islam di Masa Rasulullah pada Periode Mekkah dan Periode Madinah

pelajaran yang buruk agar bisa dihindari. Ada banyak contoh cerita didalam Alquran yang bisa dijadikan pelajaran.

e. Pembiasaan. Pendidikan dengan menggunakan pembiasaan adalah hal yang penting pada zaman Rasulullah karena merubah sifat-sifat manusia yang buruk menjadi baik perlu pembiasaan yang memerlukan waktu agar terbiasa. ${ }^{28}$

\section{Simpulan}

Dari pembahasan di atas dapat kita ketahui bahwa berita kehadiran seorang nabi akhir zaman sudah sudah lama diketahui oleh kaum yahudi dan nasrani, seperti mengetahuinya mereka dengan anak-anak mereka tetapi kebanyakan dari mereka tidak mengakui bahwasanya nabi Muhammad saw adalah seorang rasul.

Pendidan yang berlangsung pada zaman Rasulullah bersifat totalitas. Artinya Rasulullah sebagai guru memberikan perhatiannya menyeluruh pada pengembangan segenap aspek manusia mencakup pembinaan rohani, jasmani, intelektual, emosional dan spritual.

Secara umum perkembangan pendidikan Islam pada zaman Rasulullah diklasifikasikan menjadi dua periode yakni periode Mekkah dan Madinah. Terdapat beberapa karakteristik yang membedakan anatara kedua periode ini terutama dilihat dari titik tekannya materinya. Pada periode Makkah titik tekan pendidikan Islam yang paling menonjol adalah penekanan pada penanaman dan pembinaan fondasi tauhid dan akhlak. Sedangkan materi pada periode Madinah yaitu memantapkan ajaran tauhid yang di periode Mekkah dan mengajarikan syariat yang lebih luas. $325-363$

${ }^{28}$ Muhammad Quthb, Sistem pendidikan Islam, (Bandung: al-Ma'arif, 1988), h.

Jurnal Ilmiah Al QALAM, Vol. 11, No. 24, Juli-Desember 2017 
Gusti Irhamna Husin: Pemikiran Tentang Sistem dan Kelembagaan Pendidikan Islam di Masa Rasulullah pada Periode Mekkah dan Periode Madinah

Berkembang berbagai lembaga pembelajaran lahir pada zaman Rasulullah diantaranya, Darul Arqam, Kuttab, Mesjid dan Suffah membuat pendidkan pada masa Rasulullah menjadi berkembang 
Gusti Irhamna Husin: Pemikiran Tentang Sistem dan Kelembagaan Pendidikan Islam di Masa Rasulullah pada Periode Mekkah dan Periode Madinah

\section{Daftar Pustaka}

'Ali, Hasan Abdul, At-Tarbiyah al-Islamiyah Fi al-Qurni al Rabi al Hijry, Mesir: Darul Fikri.1977

Abrasyi, Muhammad Athiyah, Dasar-dasar Pokok Pendidikan, alih bahasa Bustami A. Ghani dan Djohan Bahri, Jakarta: Bulan Bintang, 1970

Bakar, Istianah Abu, Sejarah Peradaban Islam, Cet I, Malang: UIN Malang Press. , 2008

Haikal, Muhammad Husain, Sejarah Hidup Muhammad, Jakarta: Pustaka Nasional., 2010

Hasan, Hasan Ibrahim, Tarikh al Islamiyah al Siyari al Dini al Tsaqafi wal Ijtima 'I, Mesir: Maktabat al Nahdah, 1976

Husaini,Al-hamid,Riwayat Kehidupan Nabi Besar Muhammad saw, Bandung: Pustaka Hidayah, 2011

Ibrahim, Rustam, Sejarah Islam, Jakarta: Djajamurni, 1971

Jabbar Umar Abdullah, : خلاصة نور اليقين فى سبرة سيد المرسلين , Surabaya: Nurul Hikmah, jld 1.

Khaldun, Ibn, Muqaddimah, terj. Ahmadie Thoha, Cet. II, Jakarta: Pustaka Firdaus., 2002

Mursyi, Muhammad Munir, Al-Tarbiyyah Al-Islamiyyah: Ushuluha wa Tathowwuruha Fi Al Bilad Al-Arabiyyah, Kairo: Al-Kutub, 1977

Mursyi,Muhammad Munir,al-Tarbiyah al-Islamiyah, Kairo: Dar al Kutub, 1982

Quthb, Muhammad, Sistem pendidikan Islam, Bandung: al-Ma'arif, 1988

Syalabi, Ahmad, Sejarah Kebudayaan Islam I, Cet IX,Jakarta: al- Husna, 1977

Syayuthi, Hafiz jalaluddin _لتاريخ الخفاء _darul kitab Islamiyah

Jurnal Ilmiah Al QALAM, Vol. 11, No. 24, Juli-Desember 2017 
Gusti Irhamna Husin: Pemikiran Tentang Sistem dan Kelembagaan Pendidikan Islam di Masa Rasulullah pada Periode Mekkah dan Periode Madinah

Syukur, Fatah, Sejarah Peradaban Islam, Semarang: PT Pustaka Rizki Putra, 2011

Yatim, Badri, Sejarah Peradaban Islam, Jakarta: PT Raja Grafindo Persada, 2006 